American Journal of Applied Sciences 1(4): 261-265, 2004

ISSN 1546-9239

(C) Science Publications, 2004

\title{
Key Success Factors of 3rd Generation Mobile Network Services for M-Commerce in Malaysia
}

\author{
Saravanan Muthaiyah \\ Faculty of Management, Multimedia University, \\ Jalan Multimedia 63100 Cyberjaya, Selangor, Malaysia
}

\begin{abstract}
While there has been a great deal of excitement in view of M-commerce, very little is actually known about conditions and critical success factors for successful introduction of the 3rd generation mobile network services here in Malaysia. This study investigates the factors for successful diffusion of $3 \mathrm{G}$ network services and their role in advancing an interactive marketplace. $3 \mathrm{G}$ which simply means 3rd generation mobile communications technology has been widely discussed by many telecommunications service providers. It was launched by the International Telecommunication Union (ITU) some 13 years ago. 3G is viewed as an enabler of M-Commerce here in Malaysia. However, true success of this technology depends on various factors. The objective of this study is to investigate significant key enablers of $3 \mathrm{G}$ deployment and adoption in Malaysia. An insight into the critical factors to be considered for the deployment of $3 \mathrm{G}$ technology in Malaysia and experiences of other countries will be used as a benchmark to understand the mitigating factors of $3 \mathrm{G}$ deployment. Critical factors such as cost to of service, interoperability of standards, insufficiency of mobile services or content and deficiency of the laws will be discussed in this study. The study also discusses diffusion barriers and drivers for the rapid service diffusion of $3 \mathrm{G}$ mobile networks.
\end{abstract}

Key words: 3rd Generation Mobile Communication, M-Commerce, CDMA and Security

\section{INTRODUCTION}

Third generation mobile network or better known as $3 \mathrm{G}$, is a wireless communication system for a range of radio technologies that are designed to enhance the capabilities for radio-based networks. $3 \mathrm{G}$ is considered a necessary underlying infrastructure for the $\mathrm{m}$ commerce in the future. Its main objective lies in upgrading the performance of cellular networks and supporting wireless data and multimedia services. It is commonly expected that the third generation mobile network will enhance both the speed of the data transfer and the capacity of the network compared to second generation mobile networks.

Since mobile cellular businesses rolled out in the early 1980s, wireless technologies have evolved from one generation to another, with the $3 \mathrm{G}$ is superior as compared to the preceding ones. First generation (1G) mobile cellular networks employed analog technology. The second-generation (2G) later came in with the digital technology. Towards the end of 2002, the world has almost completed the transition from analog to digital cellular networks. 3G systems were introduced to the world when there is the need for faster speed, global compatibility and multimedia services.

This, however, does not mean a fast mobile connection to the World Wide Web. It is an establishment of new ways to communicate, access information, conduct business, learn and be entertained. In a whole, 3G paved the way to cater for telecommunication service convergence. With access to any service anywhere, anytime, from one terminal, the barriers towards communication will ultimately be nonexistent. Nevertheless, 3G did not solely focus on applications requiring high-speed data rates. It is about convenience and speed of access.

The new telecommunication systems will provide value added personal assistant services. Historical information about personal transactions (from the credit card issuer, from Amazon.com, the virtual stock broker and from the grocery around the corner) in combination with the settings of a personal profile on the personal web portal of the telecommunications network operator, will provide services to each of us. The communication services of the future will not be limited to voice and text messages. The current voice-only cellular phone device will evolve into a multi-functional, multimedia device that will be able to get access to the Internet and to transmit and receive video, still video, data and text (and voice, if real time communication is needed).

$3 \mathrm{G}$ is designed with the functions to provide a wide range of market-focused applications, catering for instant or real-time multimedia communications, enabling global mobility and roaming as well as offering high-speed email and Internet access. 3G enables users to transmit voice, data and even moving images. Besides that, $3 \mathrm{G}$ also allows transmission of large-scale data and moving contents photographed with digital cameras and videos. In order to effectively cater for these services, the data transmission speed need to be increased up to $144 \mathrm{Kbps}$ in a high-speed moving environment, 384Kbps in a low-speed moving environment and $2 \mathrm{Mbps}$ in a stationary environment. Nevertheless, the maximum speed of $2 \mathrm{Mbps}$ is 
expected to be possible only by the year 2005 . Consistent with the emerging trends of $3 \mathrm{G}$ mobile communication, a new business model has been developed. The boundaries between telecommunication and the applications of information technology sectors are fast becoming indistinct.

On 31 July 2002, the Malaysian Communications and Multimedia Commission (MCMC) assigned two of the three available $3 \mathrm{G}$ spectrum blocks in Malaysia. It was no surprise the two successful bidders were Telekom Malaysia Bhd and the Maxis Communications subsidiary UMTS (Malaysia) Sdn Bhd. Malaysia has plans to introduce 3G services in 2005 and the government expects both these local telecommunication giants to at least put up a modest launching next year to create awareness and appreciation of the new mobile technology to the mass market.

In some Asian markets like Malaysia, customers have to get used to mobile data services first and so far, GPRS usage has not been that strong. Malaysia's Maxis Communications, Taiwan's 3G Mobile Network and Singapore Telecom have said they are unsure if mobile users will embrace the technology. All three operators plan to launch $3 \mathrm{G}$ services in their markets in the first quarter of 2004. Taiwan's 3G Mobile Network and Singapore Telecom have said they are unsure if mobile users will embrace the technology. All three operators plan to launch $3 \mathrm{G}$ services in their markets in the first quarter of 2004. Maxis chief executive Jamaludin Ibrahim told Reuters that he would be cautious in launching 3G services, as initial subscriber demand would be slow. Mohd. Jafri Kudus, vice president and head of Celcom's mobile data division share the same view that demand has to be present before rolling out the services.

Like many countries, Malaysia is just beginning its move to the wireless Internet as the stepping stone to 3G. This doesn't mean that foreign partners will necessarily flock to Malaysia (even if they're invited). The sort of raunchy branding that Virgin has placed on its mobile offerings in recent times is unlikely to be a hit in Malaysia. But equally, Malaysia should be willing to learn some of the hard lessons that leading-edge countries like Korea have learnt over the last few years. Most of the basic drivers towards mobile Internet are just that - basic and common to most people. From 3G to succeed in Malaysia, it will need local developers to take the lessons of successful services overseas and adapt them to the local context.

According to ${ }^{[1]}$, the road ahead will be rocky. Managing the seamless progression of existing customers to the next generation of $3 \mathrm{G}$ service offerings will be crucial and the mobile industry will have to adopt a different business paradigm. Consumers will be driven away if they do not see value in the service - costs will have to commensurate the applications. In countries where the licensing process has been completed, the rollout of $3 \mathrm{G}$ services has been rather disappointing.

Market demand, handset availability and network interoperability were among the contributing factors cited. Many countries, especially developing countries, have yet to license or deploy $3 \mathrm{G}$ networks, which is very costly. In the hindsight, this could prove to be a blessing. They have learned from the mistakes of the developed countries and develop strategies that benefit their own context, economically and technologically.

The literature survey also shows that there are still significant challenges in $3 \mathrm{G}$ network deployment. There are at least 2 main competing standardsWCDMA and CDMA-2000 in the market. Network deployment is facing delays and financial trouble. Most of the network operators are not sure if users will embrace the technology. Even though some operators have started to deploy the $3 \mathrm{G}$ network or planning to deploy in 2004, most of them will proceed cautiously because they expect demand will be slow initially. There are predictions that demand picked up only in 2005 or 2006 after handset technical glitches are resolved, prices become more appealing to customers and most applications are available.

Mobile commerce, or wireless e-commerce, will provide the platform for several industries to address existing customers, provide them with better services and also give them the ability to get to new customers. The information for all transactions is used to generate personality profiles, which makes it easy to draw conclusions about personal interests of each customer. Based on these profiles, wireless coupons will inform us about current offers. Instant messengers technology, the small applications currently used on Internet home pages, which can inform us if one of our friends is online or if a flight is delayed, will be put into cellular networks. We will be able to program the cellular device to indicate if a specific person is within a certain distance. All of these possibilities are "just the tip of an enormous iceberg.

\section{RESULTS AND DISCUSSION}

Readiness in terms of cost - to the consumer: Customer behavior anchored strongly in PC usage and easy availability of "free" or low cost services like the Internet. Income influences the penetration level of mobile technology as well as the optimum combination of different generations of mobile phones. High income allows potential adopters to afford higher prices while embracing an innovation ${ }^{[2]}$. In an international context, it can be argued that an economy's standard of living and level of economic development influence the adoption timing as well as diffusion speed ${ }^{[3,2,4]}$. A certain minimum level of income is therefore a prerequisite for effective penetration level of mobile technology.

For example, third and fourth generation mobile phones are likely to be more attractive for high-income economies than for low-income economies. According to Research Company Taylor Nelson Sofres, in Malaysia there is a clear disparity between acceptance level and high interest for $3 \mathrm{G}$ applications and services 
by mobile phone users and the willingness to pay. It seems very likely that for some years the $3 \mathrm{G}$ device will be too expensive for any but the higher end customer. Consumers do not care about the infrastructure technology. It is the availability and price of data enabled handsets, useful applications and premium content that will drive consumer demand, whatever underlying technology is used to provide it.

Readiness in terms of cost-to the operators: Cost is always the resource needed to roll out any new products. Especially for technology products, the cost of setting the infrastructure for $3 \mathrm{G}$ deployment could come up to several billion of dollars, some might end up with tens of billions. The $3 \mathrm{G}$ service is a key demand and then comes the cost of new infrastructure for the deployment of the new technology. It is estimated that Malaysian companies would have to spend about RM3.8 billion to build required infrastructure such as trunk facilities, fiber optics, electronics, switching equipment, antenna, power and radio equipment for the development of new Radio Base Station (RBS).

Apart from the infrastructure cost, the Malaysian companies would also have to deal with high implementation cost with the initial investment range between RM200 million to RM350 million. These do not include the cost of developing services and application, which is too overwhelming. The roll out of $3 \mathrm{G}$ is expected to cost in the region of RM8 billion over a 10-year period for both Telekom Malaysia and Maxis. The stakes are high for all parties concernedand hence so are the risks involved. Furthermore, the cost of advertising through different media, will also incur substantially.

Diffusion of innovations theory: Although $3 \mathrm{G}$ networks are able to deliver multimedia services and mobile Internet to any $3 \mathrm{G}$ device anywhere, anytime and at any place, a full range of services must be offered in order to achieve reasonable payback periods (PBP) and not to mention the Return On Investment (ROI). According to the diffusion of high-tech products' perspective, high-end services and products are introduced at a premium price and are initially adopted by innovators and some early adopters then later, mass market usually adopts most of the services and prices fall (Fig. 3). As shown in the Figure diffusion of interactive innovation is slower than that of non-interactive innovation in earlier stage.

However, once a critical mass is reached, the interactive innovation penetrates at a much faster rate. Since most of the new telecommunication services in 3 $\mathrm{G}$ are interactive, their diffusion will display the pattern of interactive innovation. That is, telecommunications innovations usually diffuse relatively slowly in their very early stages, but once a critical mass occurs the rate of adoption takes off very rapidly. According to
Rogers (1996), critical mass occurs at the point at which enough individuals have adopted an innovation so that the innovation's rate of adoption becomes self sustaining.

In the diffusion of $3 \mathrm{G}$, both operators and service providers will have to follow a different business model in expanding the third generation mobile marketplace. Critical mass will have to be reached very quickly.

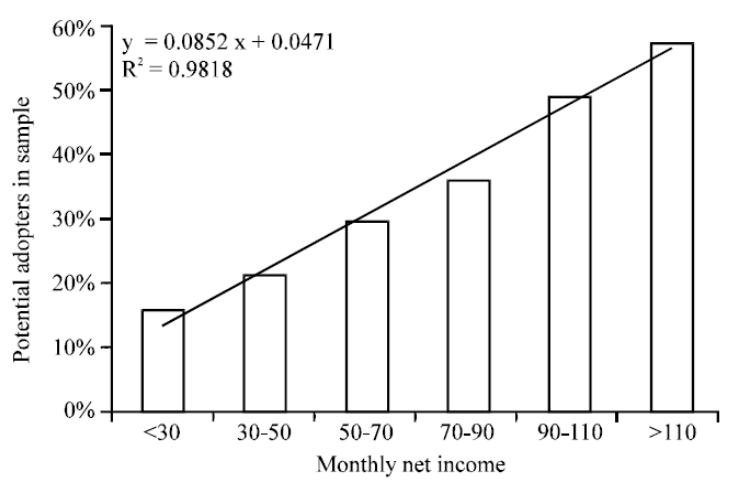

Fig. 1: Propensity to Adopt Cellular by Income A Far Eastern country, sample 1,500 interviews 1996. The correlation between propensity to adopt mobile services and income. An example of lower income group in a country. Income does matter

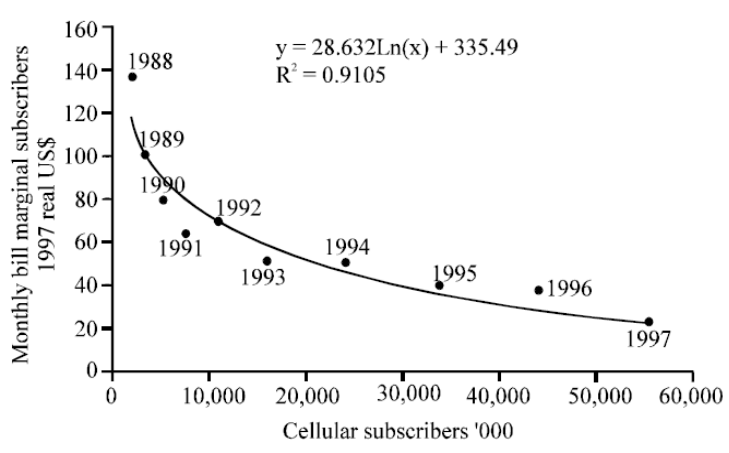

Fig. 2: Price elasticity of demand empirical evidence. Demand is driven by the value proposition, minutes for an amount of money

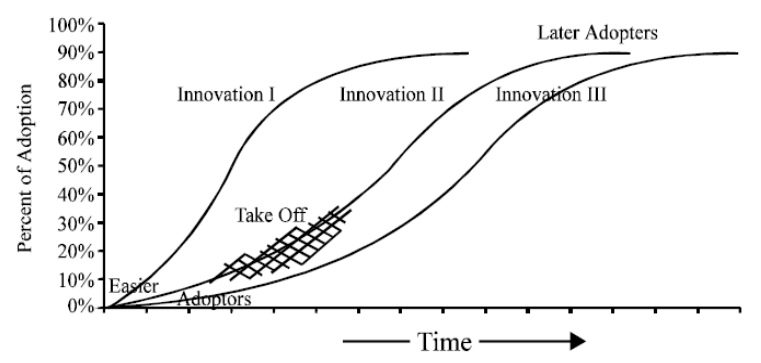

Fig. 3:Diffusion of Innovations Theory Source: Thesis Defense, Hans Pichler 3G Service Diffusion, Vienna (March 2000) 
Table 1: License Fees Paid by Telecommunication Companies in Europe (Source: Cellular-News, 2002)

\begin{tabular}{lll}
\hline Countries & Successful bidder & License fees (US\$) \\
\hline France & SFR & 551 million (RM2.1 billion) \\
Germany & MobilCom & 7.6 billion (RM28.9 billion) \\
Italy & Omnitel & 2.03 billion (RM7.7 billion) \\
United kingdom & Vodafone & 9.4 billion (RM35.7 billion) \\
\hline
\end{tabular}

Table 2: Comparative Estimates of 3G License Costs Source: Cellular-News, 2002

\begin{tabular}{llll}
\hline Country & $\begin{array}{l}\text { Estimated Adult } \\
\text { Population * }\end{array}$ & Cost of License & $\begin{array}{l}\text { Cost per } \\
\text { Population }\end{array}$ \\
\hline Malaysia & 14.5 million & $\begin{array}{l}\text { RM100 million } \\
\text { for 2 licenses }\end{array}$ & RM7.05 \\
Singapore & 3.5 million & $\begin{array}{l}\text { S } \$ 300 \text { million for 3 } \\
\text { licenses (RM648 million) }\end{array}$ & RM185.15 \\
Australia & 15.2 million & $\begin{array}{l}\text { A1. 17 billion for 4 } \\
\text { Licenses (RM2.36 billion) } \\
£ 22.5 \text { billion for 5 licenses } \\
\text { (RM135.9 billion) }\end{array}$ & RM155.30 \\
$\begin{array}{llll}\text { United } \\
\text { Kingdom }\end{array}$ & R8.2 million 819.50 \\
*Adult population is defined as populace aged 15 years and above
\end{tabular}

The networks are so expensive that the roll out just for high end users would not lead to a positive business case-the division into the mass and mainstream market would take too long. It may be said that without a full range of $3 \mathrm{G}$ terminals from the very beginning, the diffusion of services on third generation mobile networks could be delayed by some years or even fail.

Exorbitant licensing fees: $3 \mathrm{G}$ license in Europe attracted a large number of criticisms because of the exorbitant price demanded. Table 1 illustrates the prices paid by Telenor (Norway - US\$11.2 million), Telecel (Portugal-US\$90 million) and diAx (SwitzerlandUS\$29 million).

Due to the exorbitant prices of $3 \mathrm{G}$ licenses in Europe, the Malaysian Government has wisely decided to restrict the cost of 3G license to RM100 million for both spectrums, resulting in a cost of only RM7.05 per adult population in Malaysia. The cost of building a 3G infrastructure in Malaysia is expected to be in the region of RM8 billion in two Malaysian telecommunication companies in the next ten years. Hypothetically, the cost of $3 \mathrm{G}$ to the average Malaysian populace is around RM351.72 (inclusive of the RM100 million license fees), with a cost of RM5 billion to install 3G networks throughout the major cities and towns in the country. With the average Malaysian mobile subscriber paying RM30-RM60 in monthly access fees (this fee is waived for prepaid services), it will be a major challenge for the local telecommunication companies (namely Telekom Malaysia and Maxis) to push the cost of $3 \mathrm{G}$ deployments to end users. The fees however, are much lower than in the UK, Singapore and Australia (Table 2).

Readiness in terms of Killer Applications: Despite all the hype and expectations over 3G technology, 3G contents and applications have not taken off at a rate comparable to the technology involved. This is rather surprising since the availability of content is a key factor to be considered in implementing 3G technology.
Applications that are appealing to the current generation of $3 \mathrm{G}$ consumers, such as sending/receiving emails, taking pictures via a $3 \mathrm{G}$ phone and application contents are already supported by the existing $2.5 \mathrm{G}$ technology.

Many have asked, "why on earth launch a service that doesn't even exist in its first stage?" The 3G network is referred to as a video network, allowing users to send pictures or video messaging and there seems to be many technological capabilities of $3 \mathrm{G}$ including integrating computer and communications functions in a single mobile device. However, without a complete countrywide network, this service is good for little else.

In addition, the presence of other competing technology such as WLAN's and WiFi hotspots and the lack of "killer application" will discourage consumer from using $3 \mathrm{G}$ and hinders its growth. The performance will not be the optimum because with $2 \mathrm{Mbps}$ voice and data will be running at the same frequencies.

As such, development of $3 \mathrm{G}$ contents will need to introduce both content and applications that are unable to be supported by the existing 2-2.5G mobile technology. There is no point in paying a premium for $3 \mathrm{G}$ technology when the current GSM technology is adequate to satisfy consumer demands. It would be another two to three years before $3-G$ services become fully affordable.

Another potential stumbling block for 3G deployment is the absence of a single unifying standard. This has given rise to interoperability issues amongst handsets manufacturers and network operators. The new 3G network has had many problems including its inability to provide adequate coverage and its lack of handsets out on the market.

Readiness in terms of Technology, Infrastructure and Standards: Standard division has created interoperability issues for manufacturers of $3 \mathrm{G}$ handsets and network operators. This could potentially hamper the growth of $3 \mathrm{G}$ to provide accessibility anytime, anywhere. If this complication persist, the vision of "global roaming" is unlikely to be released in the near future. We are already seeing different standards being adopted in some of the world important economies-the US, Europe, China and Japan. It is hoped that the drive for globalization will eventually push these economies to find a way to integrate these standards or share their resources. Only then, a truly seamless and border-less communication can be achieved.

Though Europe's standards aren't as diversified as those in the US, the continent is facing a mix of GSM, GPRS and UMTS. According to Nancy Konish (2001), operators will have to run hybrid networks consisting of those three elements in order to implement 3G. Schema's UMTS OptiPlanners was created to relieve this burden. This is a network-planning product, which is aimed at enabling successful migration and subsequent revenue generation, by facilitating the automatic optimization of the radio frequency environment. 
Table 3: Key Success Factors for 3G Services

Key Success Factors of $3 \mathrm{G}$ services for Service

Providers:

Key Success Factors of the 3G Services for the

Cooperation and partnership on the $3 \mathrm{G}$ value chain Consumers:

Market segmentation and targeting effectiveness

Value added (cheaper, faster, and/or more convenient than the alternatives)

Fast introduction and application of services

Overcoming psychological barriers

Target marketing efficiency

Good financial situation (should be sustainable)

Personalized and/or customized services

Reaching a critical mass

The full range of services

Ease of use

Compatible with the culture

Plausible state legislation and regulations

Pricing effectiveness (Packaging)

Reliability of service (no down time)

Reliability of the content

Security

By influencing system-wide parameters, such as antenna configuration and transition levels, Schema's UMTS OptiPlanners provides heightened performance capabilities. It also reduces the need for new infrastructure and engineering resources by using existing GSM site locations. With built in prediction capabilities, the tool can show details of the future network. It also points out potential weaknesses, like physical limitations and activity costs. To broaden its targets, Schema's UMTS OptiPlanners accommodate multi-vendor environments.

\section{CONCLUSION}

Despite all the setbacks and problems faced by $3 \mathrm{G}$, we believe the time for $3 \mathrm{G}$ will come. It certainly has a major role to play in the move towards the next level of wireless technology in Malaysia. Maybe the current disappointment stems from the hypes that have been overly played or marketed by various quarters, analysts or even telecommunication companies themselves. One thing for sure is that success for $3 \mathrm{G}$ in Malaysia will not come overnight. History has taught us that other mobile technologies have taken some time to actually prosper and gain consumer acceptance. $2 \mathrm{G}$ or GSM took about 10 years to mature and become widely accepted.

There will be no exception for 3G. Success will again call for the tremendous efforts and cooperation between stakeholders, governments, network operators, contents and devices vendors and consumers. All is not lost in the midst of the criticisms, setbacks and depressed outlooks. The pieces are falling into place, slowly but surely. In short the Table below summarizes the issues that are critical for users and service providers.

\section{REFERENCES}

1. Gerald Kong, 2003. Is the timing right for $3 \mathrm{G}$ in Malaysia?, KPMG Consulting Sdn Bhd. URL: http://www.kpmg.com.my/cgibin/ kpmg.dll/kpmg/scripts/index.jsp

2. Dekimpe, M. G., P. M. Parker and M. Sarvary, 2000. Global Diffusion of Technological Innovations: A Coupled-Hazard Approach, J. Marketing Res., XXXVII: 47-59.

3. Antonelli, C., 1993. Investment and Adoption in Advanced Telecommunications, J. Econ. Behavior and Org. pp. 227-45.

4. Gruber, H. and F. Verboven, 2001. The Diffusion of Mobile Telecommunications Services in the European Union. European Economic Review, 45: 677-588.

5. Rogers, E.M., 1995. The Diffusion of Innovations, 4th edn. New York: Free Press.

6. Nancy Konish, 2001. The tool helps to plot Europe's 3G networks, Wireless System Design, pp. 9. 